\section{Measurement of troponin in cardiomyopathies}

\author{
Andrew Connelly, ${ }^{1}$ lain N. Findlay, \\ Caroline J. Coats ${ }^{2,3}$ \\ 'School of Medicine, University of \\ Glasgow; '2nherited Cardiac Conditions \\ Clinic, Queen Elizabeth University \\ Hospital, Glasgow; ${ }^{3}$ Department of \\ Cardiology, Golden Jubilee National \\ Hospital, Glasgow, UK
}

\section{Abstract}

Troponins are thin myofilament proteins that regulate the contraction of cardiac and skeletal muscle. The cardio-specific troponin I (TnI) and $\mathrm{T}$ (TnT) proteins are sensitive and specific biomarkers of myocardial injury which over the past twenty years have revolutionised the diagnosis and management of myocardial infarction. With the advent of high sensitivity assays the role for cardiac troponins is possibly expanding. Elevated levels are associated with adverse cardiovascular events and mortality in heart failure and the general population. Studies in cardiomyopathies are generally small with $<200$ patients, but serum troponin levels can be chronically raised and detect subclinical myocyte damage. This review examines all major published studies of cardiac troponin measurement in cardiomyopathies. There is considerable variability among studies regarding assays used and definitions of abnormal results but elevated troponin levels are almost invariably related to poor prognosis and their negative predictive value is important.

\section{Troponin and the heart}

\section{The discovery of troponin}

The discovery of actin and the actomyosin system in the 1940s provided a model with which to study the components involved in the contraction and relaxation cycle of muscle. ${ }^{1}$ It soon became apparent that adenosine triphosphate (ATP) was essential for this process ${ }^{2}$ and later that calcium was required for the activation of the MgATPase of the myofibrils. ${ }^{3}$ In 1963 Ebashi reported a new myofibrillar protein, troponin, which was the target for calcium. ${ }^{4}$ By 1972 , troponin was demonstrated to be a complex of three proteins, troponin $\mathrm{C}$, I and T. ${ }^{5,6}$ Subsequent developments revealed that each protein is under the control of individual genes and has isoforms specific to the muscle type. Over the last 20 years cardiac troponins have emerged as sensitive and specific biomarkers of myocardial injury and transformed the management of myocardial infarction (Figure 1).

\section{Troponin genes}

Several troponin genes (Table 1) have been described based on molecular cloning in humans and other vertebrates. Each of these genes is subject to alternative splicing, resulting in the production of multiple tissue-specific isoforms. Mutations in all the troponin genes expressed in the heart have been linked to familial cardiomyopathies (Table 2).

\section{Troponin proteins}

The troponin genes encode different protein isoforms, which are expressed in a tissue specific manner (Table 3). Two troponin genes, TNNI3 and TNNT2 are highly specific to cardiac tissue encoding cardiac troponin I (TnI) and $\mathrm{T}(\mathrm{Tn} \mathrm{T})$ respectively. Although only one protein isoform has been described for TNNI3, 12 different isoforms have been described for TNNT2 and are produced by alternative splicing. ${ }^{7}$ Isoform 6 predominates in normal adult heart. Isoforms 1, 7 and 8 are expressed in fetal heart. Isoform 7 is also expressed in failing adult heart. The fetal heart shows a greater expression of TNNT2 in the atrium than in the ventricle, while the adult heart shows a greater expression of TNNT2 in the ventricle than in the atrium. ${ }^{8}$ Together these cytoplasmic troponin proteins form a regulatory troponin complex which interacts with actin and alpha tropomyosin in the thin filament of skeletal and cardiac muscle sarcomeres. ${ }^{9}$

\section{Cardiac troponins as clinical biomarkers}

Troponins transiently leak out of the myocyte when it is damaged, for example by acute ischaemia. They have therefore been used as biomarkers of myocardial injury and their release kinetics make them particularly suitable for diagnosis of acute coronary syndromes. ${ }^{10,11}$ Cardiac troponins have also shown some potential as predictors of disease progression and mortality in other cardiac conditions such as aortic stenosis, ${ }^{12}$ stable coronary artery disease ${ }^{13}$ and chronic heart failure. ${ }^{14}$

\section{Development of clinical troponin assays}

Immunoassays for TnI and TnT were developed in the 1980s. ${ }^{15,16}$ Troponins proved to be more specific for cardiac damage and more persistently elevated [thus allowing for the diagnosis of later acute coronary syndrome (ACS) presentations] than competing cardiac
Correspondence: Caroline J. Coats, Department of Cardiology Golden Jubilee National Hospital, Agamemnon Street, Glasgow, G81 4DY, United Kingdom.

Tel.: 0141.951.5000.

E-mail: carolinecoats@doctors.org.uk

Key words: Troponin; biomarkers; cardiomyopathy.

Conflicts of interest: there are no conflicts of interest to declare.

Received for publication: 27 September 2016. Revision received: 14 November 2016.

Accepted for publication: 8 December 2016.

This work is licensed under a Creative Commons Attribution NonCommercial 4.0 License (CC BYNC 4.0).

(C) Copyright A. Connelly et al., 2016

Licensee PAGEPress, Italy

Cardiogenetics 2016; 6:6306

doi:10.4081/cardiogenetics.2016.6306

biomarkers such as creatine kinase MB. ${ }^{17,18}$ Mounting evidence led the European Society of Cardiology and American College of Cardiology to describe troponins as the preferred marker for myocyte injury and formal inclusion in clinical practice guidelines in 2000. ${ }^{19,20}$ The early assays were refined to decrease the rate of false-negative results in the presence of anticardiac troponin autoantibodies. ${ }^{1}$

\section{High sensitivity assays}

The recent transition to highly sensitive troponin (hs-Tn) assays in clinical practice has encouraged the hunt for an expanded role. Whilst increased sensitivity allows for more rapid and precise diagnosis and earlier rule out of acute coronary syndrome (ACS), the major disadvantage is the potential for unnecessary, invasive and expensive investigations. ${ }^{22}$ Defining abnormal levels and interpreting results is challenging for several reasons: there are a variety of assays being produced by different manufacturers, a broad range of conditions can increase hs-Tn and even healthy individuals can have elevated levels. ${ }^{23,24}$

\section{Value of troponin measure- ment in cardiomyopathies}

Whilst mutations in the troponin genes are well recognised to cause cardiomyopathy, measurement of the protein in plasma or serum is gaining increasing attention as useful biomarkers to stage cardiovascular disease, stratify treatment and predict prognosis. 
Table 1. Human troponin genes.

\begin{tabular}{|c|c|c|c|c|}
\hline Gene name & Cytogenetic location & HGNC Symbol & HGNC Identifier & UniProt Identifier \\
\hline Troponin T1, slow skeletal type & $19 q 13.4$ & TNNT1 & 11948 & P13805 \\
\hline Troponin T2, cardiac type & $1 q 32$ & TNNT2* & 11949 & P45379 \\
\hline Troponin I1, slow skeletal type & 1q31.3 & TNNI1 & 11945 & P19237 \\
\hline Troponin I2, fast skeletal type & 11p15.5 & TNNI2 & 11946 & P48788 \\
\hline Troponin I3, cardiac type & 19q13.4 & TNNI3* & 11947 & P19429 \\
\hline Troponin Cl, slow skeletal and cardiac type & 3p21.1 & TNNCl* & 11943 & P63316 \\
\hline Troponin C2, fast skeletal type & 20q12-q13.11 & TNNC2 & 11944 & $\mathrm{P} 02585$ \\
\hline
\end{tabular}

*Genes expressed in the heart.

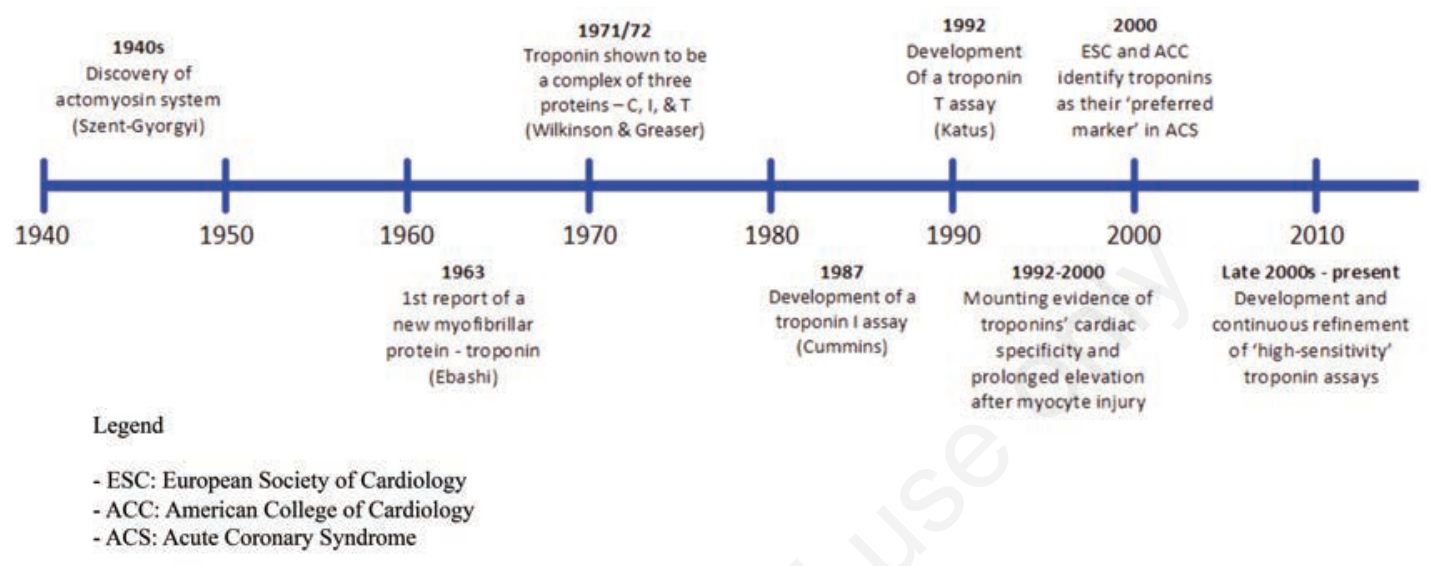

Figure 1. Timeline illustrating the history of troponin, from its discovery to its modern-day use.

It is not entirely clear why myocardial diseases should cause troponin release into the circulation. One theory is that myocyte ischaemia and necrosis result from an imbalance between the increased demands of the myocardium and its blood supply; the other is that the underlying genetic abnormalities themselves cause cellular injury and subsequent leakage of myocyte contents. ${ }^{25}$ There are several studies describing chronic troponin elevation in cardiomyopathies implying ongoing sub-clinical myocyte necrosis, apoptosis or leakage. ${ }^{26-28}$

In this section, we summarise the clinical studies that have examined the role of serum troponin measurement in each of the cardiomyopathies. We performed a comprehensive literature search by using electronic bibliographic databases (MEDLINE, EMBASE and The Cochrane Library) and combinations of the following keywords: troponin, biomarker, hypertrophic, obstructive, dilated, restrictive, Fabry, non-compaction, amyloid, peri-partum, arrhythmogenic and cardiomyopathy. Bibliographies of all selected articles and review articles were reviewed for other relevant articles.

\section{Hypertrophic cardiomyopathy}

Hypertrophic cardiomyopathy (HCM) is an autosomal dominant inherited heart muscle disorder with a prevalence of 1 in $500 .{ }^{29,30}$

Table 2. Troponin genes associated with familial cardiomyopathies.

\begin{tabular}{lccc} 
Familial cardiomyopathy & TNNT2 & TNNI3 & TNNC1 \\
Hypertrophic cardiomyopathy & $\checkmark$ & $\checkmark$ & $\checkmark$ \\
Dilated cardiomyopathy & $\checkmark$ & $\checkmark$ & $\checkmark$ \\
\hline Restrictive cardiomyopathy & $\checkmark$ & $\checkmark$ & X \\
Non compaction cardiomyopathy & $\checkmark$ & $X$ & X \\
\hline
\end{tabular}

Clinically it is defined as left ventricular hypertrophy (LVH) unexplained by loading conditions. ${ }^{31}$ Most disease-causing genes encode for proteins of the cardiac sarcomere with mutations in beta-myosin heavy chain, $M Y H 7$, and myosin-binding protein C, MYBPC3, accounting for much of human disease. Less commonly mutations in cardiac troponin genes (TNNI3, TNNT2 and TNNC1) cause HCM. Inheritance is usually autosomal dominant with variable penetrance, however mutations can arise de novo and up to $40 \%$ of patients have no identifiable mutation..$^{32}$ Family screening forms an integral part of clinical assessment, and the disease spectrum now extends to asymptomatic adults and children who carry a pathogenic mutation; these patients may have a sub-clinical phenotype with mild or no clinically detectable abnormalities. ${ }^{33}$ The frequency of patients with no identifiable mutation or symptoms, and HCM's phenotypic resemblance to other conditions such as athletic or hypertensive $\mathrm{LVH}$ can make diagnosis and screening difficult. Non-genetic biomarkers therefore have a potential role in differentiating HCM from other conditions, as well as staging and predicting prognosis. High sensitivity cardiac troponin T (hs-TnT) are associated with cardiovascular events, heart failure and death in HCM and Tn measurement is recommended as part of a laboratory work up. ${ }^{30}$ Levels are higher than in hypertension but lower in infiltrative conditions such as a amyloid. ${ }^{34,35}$

Prevalence: Increased levels of Tn (usually defined as being above the manufacturer's recommended 99th percentile cut-off point) have been reported in between $4 \%$ and $66 \%$ of patients with HCM (Table 4). By comparison, prevalence of elevated $\mathrm{Tn}$ in the general population is $0.7 \%$ using a traditional lower sensitivity TnT assay ${ }^{36}$ and up to $4 \%$ using a hs-Tn 
assay. ${ }^{37}$ Exercise can increase Tn levels. ${ }^{38}$

Clinical correlates: troponin elevation in HCM is associated with greater LV wall thickness $^{37,39-43}$ and LV mass. ${ }^{44-46}$ Two studies found Tn elevation in patients with $\mathrm{LV}$ outflow tract obstruction $^{37,42}$ but another found no correlation. ${ }^{40}$ The natural history of HCM includes progression to heart failure and Tn elevation is present in those with $\mathrm{LV}$ systolic dysfunction $37,40,44$ although the degree of hs-TnT elevation does not correlate linearly with ejection fraction. ${ }^{31}$ The relationship with New York Heart Association (NYHA) heart failure class however is conflicting. ${ }^{37,40}$ Diastolic dysfunction, usually an earlier feature in HCM is also associated with Tn release. Several studies report correlations between Tn and left atrial (LA) area or diameter ${ }^{37,42,46}$ as well as filling pressure measured by the ratio between early diastolic mitral inflow velocity and early diastolic mitral annular velocity $(\mathrm{E} / \mathrm{Ea})^{40,42}$ It is uncertain whether Tn can help detect the presence of paroxysmal atrial fibrillation (AF) with studies reporting both a positive ${ }^{40,47}$ and negative association. ${ }^{42,46}$ More recently Tn levels have been related to the presence and extent of late gadolinium enhancement (LGE) on cardiac magnetic resonance imaging (CMR). Individuals with elevated Tn have a higher prevalence of LGE. ${ }^{43,46,48,49}$ but data are conflicting on whether Tn measurement is an independent predictor of the extent of LGE. ${ }^{48,49} \mathrm{~A}$ high T2 signal on CMR, a potential marker of active tissue injury, in HCM is also associated with elevated troponin levels..$^{50}$

Prognosis: patients with HCM and elevated TnI have significantly more CV events (HCMrelated death or hospitalisation, embolic strokes, or the appearance of sustained ventricular tachycardia) than those with normal TnI over a follow-up period of 39 months. ${ }^{51}$ An adverse prognosis has also been demonstrated using a hs-TnT assay in two independent study cohorts. $^{43,52}$

Combining measurement of cardiac troponins with natriuretic peptides may provide additional value in assessing prognosis of several cardiomyopathies. In HCM, Brain natriuretic peptide (BNP) or N-terminal pro-brain natriuretic peptide (NT-proBNP) correlates with similar clinical parameters to $\mathrm{Tn}, 44,46,48,51,53$ but was superior to hs-TnT at predicting which unaffected gene mutation carriers would go on to develop HCM. ${ }^{54}$ To date there are few bio- marker studies in pre-phenotypic disease in any cardiomyopathy.

\section{Dilated cardiomyopathy}

Dilated cardiomyopathy (DCM) is defined by the presence of left ventricular dilatation and left ventricular systolic dysfunction in the absence of abnormal loading conditions (hypertension, valve disease) or coronary artery disease sufficient to cause global systolic impairment. ${ }^{31}$ It is a non-specific phenotype and the result of a wide range of cardiac insults. ${ }^{55}$ Approximately half of cases are deemed to be idiopathic. ${ }^{56}$ Many idiopathic presentations have an underlying genetic basis and unlike HCM, where relatively few mutations predominate, DCM can be caused by defects in over 60 genes. ${ }^{57}$ The common effects of these mutations are hypo-contractile cardiac myocytes, which lead to the characteristic ventricular dilatation and thinning.

Prevalence: While Tn is often raised in idiopathic DCM, several studies have shown that it is lower than in myocarditis and TnT but not hs-TnT might be useful in distinguishing these conditions ${ }^{58-61}$ (Table 5). Patients with ischaemic cardiomyopathy have greater levels of TnI than DCM patients at hospital presentation but levels are more likely to remain elevated at 3 months in DCM. ${ }^{27,62}$

Clinical correlates: the relationship between Tn and imaging parameters in DCM is less consistent than in HCM. Elevated Tn is associated with increased LV diameters and volumes but not always with ejection fraction. ${ }^{56,63,64}$ However, over 5 years of follow-up, elevated hsTnT predicted a fall in LV ejection fraction.${ }^{65}$ As for LGE, an independent predictor of mortality in $\mathrm{DCM},{ }^{66}$ only one study has investigated its relationship with $\mathrm{Tn}$, finding that hs-TnT could predict LGE extent but TnT could not. ${ }^{60}$ Elevated troponin levels and the presence of myocardial inflammation on CMR are predictors of $\mathrm{LV}$ recovery in children presenting with dilated cardiomyopathy. ${ }^{67}$

Prognosis: The relationship between troponin and prognosis in DCM appears to depend on assay sensitivity. Four studies ${ }^{26,28,65}$, ${ }^{68}$ found an association between TnT elevation and CV morbidity and mortality while three did not. ${ }^{60,69,70}$ Similarly, for TnI, three studies reported an association ${ }^{27,56,63}$ while two did not. ${ }^{65,69}$ Only hs-TnT has been found thus far to be an independent predictor of adverse cardio- vascular events in all the studies that have examined it. ${ }^{60,65,70}$ The largest study describes mortality in 310 patients admitted to hospital for decompensation of heart failure due to underlying DCM; mortality over 2.2 years was significantly higher in patients with elevated TnI compared to those with normal TnI at baseline. ${ }^{63}$ The longest follow-up study over 5.1 years describes significantly more CV events in patients with elevated TnT or hs-TnT, but not $\operatorname{TnI} .^{65}$

Overall, the most promising role for Tn in DCM is in prognostication. This fits with the role troponins have in heart failure more broadly, where higher levels have been associated with poorer clinical outcomes. ${ }^{71,72}$

\section{Restrictive cardiomyopathy}

Restrictive cardiomyopathy (RCM) is defined as restrictive ventricular physiology in the presence of normal or reduced diastolic volumes (of one or both ventricles), normal or reduced systolic volumes, and normal ventricular wall thickness. ${ }^{31}$ Familial RCM is much more rarer than HCM and DCM and no systematic studies of Tn measurement have been reported. Restrictive physiology can occur in a wide range of different pathologies including amyloid, Anderson Fabry disease and Chagas cardiomyopathy which are discussed below. ${ }^{73}$

\section{Non-compaction cardiomyopathy}

Left ventricular non-compaction (LVNC) is a challenging condition to diagnose and there is overlap both in the genetics and phenotype with other cardiomyopathies. ${ }^{31} \mathrm{~A}$ retrospective study of 71 patients found TnT was elevated in 12 (17\%) patients with LVNC and was associated with the presence of neuromuscular disease and a worse prognosis. ${ }^{74}$ An observational study of 50 patients with LVNC, stratified by ejection fraction, found elevated levels of TnI and TnT in both individuals with preserved (LVEF $>50 \%, \mathrm{n}=24$ ) and reduced (LVEF $<35 \%$, $\mathrm{n}=26$ ) ejection fraction compared with controls. ${ }^{75}$

\section{Arrhythmogenic right ventricular cardiomyopathy}

Arrhythmogenic right ventricular cardiomyopathy (ARVC) is defined histologically by the presence of progressive replacement of right ventricular myocardium with adipose and

Table 3. Troponin proteins expressed in the heart.

\begin{tabular}{ccccl} 
UniProt Identifier & $\begin{array}{c}\text { Protein } \\
\text { name }\end{array}$ & $\begin{array}{c}\text { Protein } \\
\text { Isoforms }\end{array}$ & $\begin{array}{c}\text { Mass } \\
(\mathrm{kDa})\end{array}$ & Function \\
P45379 & $\begin{array}{l}\text { Troponin T, cardiac } \\
\text { P19429 }\end{array}$ & 12 & 37 & Binds troponin complex to tropomyosin \\
\hline P63316 & Troponin I, cardiac & 1 & 22.5 & Binds actin and inhibits actomyosin ATPase activity \\
\hline
\end{tabular}


Table 4. Studies evaluating troponin in hypertrophic cardiomyopathy.

\begin{tabular}{|c|c|c|c|c|c|}
\hline Year & $1^{\text {st }}$ author & Biomarker & Population & $\begin{array}{l}\text { Frequency } \\
\text { of Tn elevation }\end{array}$ & Findings \\
\hline 2003 & Sato & $\mathrm{TnT}$ & $30 \mathrm{HCM}$ & $12 / 30(40 \%)$ & $\begin{array}{l}\text { 12/30 patients with persistently elevated TnT levels had lower FS \% and } \\
\text { greater septal wall thickness, which thinned during follow-up } \\
\text { (mean } 21.5 \text { months). } 4 / 12 \text { progressed to DCM (end stage dilated HCM) }\end{array}$ \\
\hline 2006 & Pop & $\begin{array}{l}\text { TnI } \\
\text { TnT }\end{array}$ & $7 \mathrm{HCM}$ & $3 / 7(43 \%)$ & $\begin{array}{l}\text { 3/7 young adults with HCM had elevated TnI before exercise; } 2 \text { more had } \\
\text { elevated TnI levels after exercise; only } 1 \text { had elevated TnT after exercise; } \\
\text { all diminished using a } \beta \text {-blocker }\end{array}$ \\
\hline 2006 & Taniguchi & $\begin{array}{l}\text { TnT } \\
\text { BNP }\end{array}$ & $22 \mathrm{HCM}$ & 2/22 (9\%) & $\begin{array}{l}\text { Elevated TnT in 2/22 HCM patients with CHF. } 3 / 16 \text { (18\%) had elevated TnT } \\
\text { after mean } 27.9 \text { days of CHF } \\
\text { treatment. Only } 1 \text { HCM patient had a CV event in } 2 \text { years of follow-up }\end{array}$ \\
\hline 2010 & Kubo & $\begin{array}{l}\text { TnI } \\
\text { BNP }\end{array}$ & $162 \mathrm{HCM}$ & & $\begin{array}{l}\text { Higher in males, LVSD, AF; correlated with MWT, LVESD, E/Ea. } \\
\text { Weak correlation with BNP. No correlation with NYHA or LVOTO }\end{array}$ \\
\hline 2010 & Moreno & hs-TnT & $\begin{array}{l}95 \mathrm{HCM} \\
45 \text { Control }\end{array}$ & $\begin{array}{l}40 / 95(42 \%) \\
2 / 45(4.4 \%)\end{array}$ & $\begin{array}{l}\text { hsTnT was raised in patients in NYHA } \geq 3 \text {, LVOTO, LVSD, abnormal BP } \\
\text { response, LGE. hsTnT correlated with MWT, LA diameter and LVOT gradient }\end{array}$ \\
\hline 2011 & Kubo & TnI, BNP & 167 HCM & 107/162 (66\%) & $\begin{array}{l}\text { Over } 38.5 \text { months of follow-up there were } 20 \text { CV deaths and } 14 \text { other } \\
\text { CV events. The risk of events was } 11.7 \mathrm{x} \text { higher if BNP and Trop were } \\
\text { both high compared with both low }\end{array}$ \\
\hline 2013 & Okamoto & $\begin{array}{l}\text { hsTnT } \\
\text { hsTnI } \\
\text { BNP and CK }\end{array}$ & $73 \mathrm{HCM}$ & $\begin{array}{l}19 / 73(26 \%) \\
0 / 73(73 \%)\end{array}$ & $\begin{array}{l}\text { There was a correlation between absolute hsTnT and hsTnI levels } \\
\text { and LV mass index, LVEDV, LVESV. hsTnI correlated with BNP. } \\
\text { hsTnT inversely correlated with LVEF }\end{array}$ \\
\hline 2013 & McGorrian & $\begin{array}{c}\text { TnI } \\
\text { hsTnI }\end{array}$ & $\begin{array}{l}19 \text { definite HCM } \\
24 \text { borderline HCM } \\
107 \text { total }\end{array}$ & $\begin{array}{c}\text { TnI } 3 / 17(18 \%) \\
\text { hsTnI } 4 / 19(21 \%)\end{array}$ & $\begin{array}{l}107 \text { previously un-investigated probands or relatives of HCM patients. } \\
\text { Association between TnI and hsTnI and MWT. Those deemed to have } \\
\text { borderline or definite HCM were more likely to have raised TnI or hsTnI }\end{array}$ \\
\hline 2013 & Kawasaki & $\begin{array}{l}\text { hs-TnT } \\
\text { BNP and CK }\end{array}$ & $53 \mathrm{HCM}$ & & $\begin{array}{l}\text { hsTnT and BNP was higher in patients with LGE. hsTnT, BNP and combined } \\
\text { were good for detecting LGE. LGE extent correlated with BNP but not hs-TnT. } \\
\text { hsTnT levels correlated with fibrosis during } 22 \text { months follow-up }\end{array}$ \\
\hline 2013 & Kubo & hs-TnT & $183 \mathrm{HCM}$ & 99/183 (54\%) & $\begin{array}{l}\text { Over } 4.1 \pm 2.0 \text { years of follow-up, } 32 \% \text { hsTnT +ve had CV events vs } 7 \% \text { of } \\
\text { hsTnT -ve. CV event risk also increased with magnitude of hsTnT }\end{array}$ \\
\hline 2014 & Jenab & hs-TnT & $98 \mathrm{HCM}$ & 42/98 (43\%) & $\begin{array}{l}\text { Elevated hs-TnT was associated with age, chest pain, NYHA class, LVH, NVST, } \\
\text { LAA, E/Ea, MWT, LVOT gradient; not with LVEF, AF, syncope, FH-SCD, LVOTO }\end{array}$ \\
\hline 2014 & Cramer & hs-TnT & $62 \mathrm{HCM}$ & $16 / 62(26 \%)$ & Elevated hsTnT, correlated with LV mass and MWT \\
\hline 2014 & Nakamura & hs-TnT, BNP & $102 \mathrm{HCM}$ & $37 / 102(36 \%)$ & $\begin{array}{l}\text { 37/102 (36\%) had raised hsTnT, } 24 / 97 \text { (24\%) had raised BNP. An elevated } \\
\text { hs-TnT associated with AF, but not with any other echo variables } \\
\text { (either as a continuous or a binary variable) }\end{array}$ \\
\hline 2015 & Kubo & hs-TnT, BNP & $\begin{array}{l}35 \text { HCM } \\
8 \text { amyloid } \\
3 \text { Fabry }\end{array}$ & Nenta & $\begin{array}{l}\text { hsTnT higher in infiltrative cardiomyopathy than HCM, BNP no different. } \\
\text { hsTnT was the best differentiator between infiltrative and HCM }\end{array}$ \\
\hline 2015 & Zhang & TnI, BNP & $149 \mathrm{HCM}$ & $42 / 149(28 \%)$ & $\begin{array}{l}\text { TnI raised in } 42 / 149 \text { (28\%). Associated with MWT, LV mass, } \\
\text { frequency of enlarged LA, LVEDV, LVESV, BNP, reduced LVEF; } \\
\text { but not with AF, FHSCD, syncope, NVST }\end{array}$ \\
\hline 2016 & Hamada & $\begin{array}{l}\text { TnT } \\
\text { CK and LDH }\end{array}$ & $\begin{array}{l}77 \mathrm{HCM} \\
14 \mathrm{HTN}\end{array}$ & & $\begin{array}{l}12 \text { control } 3 / 77 \text { (4\%) Long-term follow-up study - } 20 \text { years. } \\
3 \text { (4\%) of HCM patients had elevated TnT at baseline; } \\
0 \text { HTN or control patients did }\end{array}$ \\
\hline 2016 & Zhang & TnI, BNP & $163 \mathrm{HCM}$ & & $\begin{array}{l}\text { Patients with LGE had higher TnI and BNP. LGE extent correlated with } \\
\text { TnI andBNP. TnI \& MWT independently predicted LGE presence; BNP did not }\end{array}$ \\
\hline 2016 & Hasler & hsTnT & $91 \mathrm{HCM}$ & $46 / 91(51 \%)$ & $\begin{array}{l}\text { Elevated hsTnT associated with higher MWT and LGE prevalence and } \\
\text { worse exercise capacity. 15\% of +ve hsTnT has adverse events vs 7\% } \\
\text { of -ve hsTnT. Timeline of hsTnT measurement and events not defined }\end{array}$ \\
\hline 2016 & Ho & $\begin{array}{l}\text { hsTnT } \\
\text { BNP }\end{array}$ & $\begin{array}{l}38 \text { HCM genes } \\
\text { carriers without } \\
\text { hypertrophy }\end{array}$ & & $\begin{array}{l}\text { Age } 15.8 \pm \text { 8.6. Median } 2.9 \text { years F/U. } 4 \text { developed HCM - higher BNP } \\
\text { (but not hsTnT) at baseline. BNP and hsTnT increased during } \\
\text { follow-up in those who developed HCM but decreased in those who did not }\end{array}$ \\
\hline
\end{tabular}

CK, creatine kinase; LDH, lactate dehydrogenase; AF, atrial fibrillation; FS, fractional shortening; CHF, congestive heart failure; MWT, maximal left ventricular wall thickness; LVOTO, left ventricular outflow tract obstruction; LVSD, left ventricular systolic dysfunction; LVESD, left ventricular end systolic diameter; LVEDV/LVESV, left ventricular end diastolic/systolic volume; LAA, left atrial area; NSVT, non sustained ventricular tachycardia; FHSCD, family history of sudden cardiac death; F/U, follow up. 
fibrous tissue. ${ }^{31}$ Mutations in genes encoding for desmosomal proteins are detectable in 30 $50 \%$ patients but diagnosis depends on integrating structural, histological, electrocardiographic, arrhythmic and genetic features. ${ }^{76}$ Troponin release has not been systematically evaluated in this disease but there are case reports of troponin elevation associated with ventricular arrhythmia in the absence of coro- nary artery disease, postulating that $\mathrm{Tn}$ release may point toward a "hot" arrhythmic phase of the disease. ${ }^{77-79}$

\section{Fabry cardiomyopathy}

Anderson-Fabry disease (AFD) is an Xlinked lysosomal storage disease caused by deficiency of the enzyme alpha-galactosidase.
Cardiac involvement usually manifests with concentric left ventricular hypertrophy and Tn levels are typically higher than in HCM.${ }^{34}$ Early diagnosis is important because enzyme replacement therapy can halt disease progression. ${ }^{80} \mathrm{~A}$ persistent increase in $\mathrm{TnI}$ was first reported in 3 out of 14 (21\%) adults with AFD all of whom had LVH and LGE on CMR studies ${ }^{81}$ A larger $(n=62)$ study from the same centre

Table 5. Studies evaluating troponin in dilated cardiomyopathy. The study population is described as acute if patients were hospitalised and chronic if patients were stable and enrolled as outpatients.

\begin{tabular}{|c|c|c|c|c|c|}
\hline Year & $1^{\text {st }}$ author 1 & Biomarker & Population & $\begin{array}{l}\text { Frequency } \\
\text { of Tn elevation }\end{array}$ & Findings \\
\hline 1997 & Sato & $\mathrm{TnT}$ & 17 acute & 3/17 (18\%) & $\begin{array}{l}\text { 3/17 (18\%) +ve TnT. Cardiac event-free rate was significantly higher for } \\
\text { TnT/Type III procollagen/7S collagen -ve. CK level similar }\end{array}$ \\
\hline 2001 & Sato & TnT & 60 chronic & $27 / 60(45 \%)$ & $\begin{array}{l}27 / 60(45 \%)+v e \text { TnT initially. } 17 / 60 \text { (28\%) maintained +ve TnT after mean } \\
16 \text { mo of CHF treatment - their LVDd and LVEF worsened while they improved } \\
\text { for the others; their cardiac event-free and survival rates were significantly worse. }\end{array}$ \\
\hline 2002 & Soongswang & $\mathrm{TnT}$ & $\begin{array}{l}10 \text { acute DCM } \\
10 \text { myocaritis } \\
21 \text { controls }\end{array}$ & & $\begin{array}{l}10 \text { paediatric DCM patients had identical mean TnT concentrations to } 21 \text { controls, } \\
\text { and significantly less than } 10 \text { with myocarditis. CK-MB was similarly useful for } \\
\text { differentiating between DCM and myocarditis }\end{array}$ \\
\hline 2004 & Aso & $\begin{array}{c}\text { TnT } \\
\text { Tenascin-C }\end{array}$ & 31 chronic & 9/31 (29\%) & TnT and Tenascin-C correlated \\
\hline 2005 & Soongswang & $\mathrm{TnT}$ & 19 acute & & $\begin{array}{l}\text { TnT useful for distinguishing myocarditis from DCM (higher in former). } \\
\text { TnT levels did not correlate with adverse outcomes in DCM } \\
\text { (which may be due to timing of the blood sampling) }\end{array}$ \\
\hline 2006 & Nellessen & TnI & 33 acute & & $\begin{array}{l}\text { TnI elevated in both idiopathic }(\mathrm{n}=33) \text { and ischaemic }(\mathrm{n}=25) \text { ( }>\text { in ischaemic) } \\
\text { at baseline and after } 3 \text { months follow-up. However ischaemic CM TnI decreased, } \\
\text { idiopathic DCM's TnI did not. TnI was a predictor of mortality }\end{array}$ \\
\hline 2006 & Taniguchi & $\begin{array}{l}\text { TnT } \\
\text { BNP }\end{array}$ & 41 mixed & $8 / 41(20 \%)$ & $\begin{array}{l}\text { Patients being investigated for CHF. } 8 / 41 \text { (20\%) TnT +ve. } 7 / 36(19 \%) \text { remained +ve } \\
\text { after mean } 38.7 \text { days F/U. Significantly higher adverse CV event rates in TnT +ve } \\
(3 / 8(38 \%) \text { vs 5/33 (15\%) }\end{array}$ \\
\hline 2007 & Miller & $\begin{array}{l}\text { TnT } \\
\text { TnI } \\
\text { BNP }\end{array}$ & 13 chronic & & $\begin{array}{l}\text { All biomarkers significantly higher in ischaemic CM vs idiopathic DCM. Baseline } \\
\text { TnT/TnI did not predict mortality }\end{array}$ \\
\hline 2008 & Miettinen & $\begin{array}{l}\text { TnI } \\
\text { BNP }\end{array}$ & 95 chronic & 14/95 (15\%) & $\begin{array}{l}\text { 14/95 (15\%) TnI +ve. Consistent over mean } 4.1 \text { years F/U. LV dimension, volume } \\
\text { and LVEF correlated with TnI level. } \\
\text { Fewer end-points (CV death, transplant, ICD) if normal TnI }\end{array}$ \\
\hline 2011 & Frankenstein & hsTnT & 24 chronic & 8/24 (33\%) & 8/24 (33\%) +ve hsTnT (71\% for IHD)/ No correlation with LVEF \\
\hline 2011 & Kawahara & $\begin{array}{l}\text { TnT } \\
\text { hsTnT } \\
\text { BNP }\end{array}$ & 85 chronic & $4 / 85(5 \%)$ & $\begin{array}{l}\text { 46/85 (54\%) } \quad \text { 4/85 (5\%) TnT +ve, 46/85 (54\%) hsTnT +ve. 31/85 } \\
\text { (36\%) TnT detectable, 76/85 (89\%) hsTnT detectable. During median F/U } 4.1 \text { years, } \\
20 \text { CV deaths - hsTnT, but not TnT, was a significant prognostic predictor }\end{array}$ \\
\hline 2013 & Sramko & $\begin{array}{l}\text { TnT, } \\
\text { hsTnT } \\
\text { BNP }\end{array}$ & 27 chronic & $7 / 27(26 \%)$ & $\begin{array}{l}\text { 12/27 (44\%) } 7 / 27(26 \%) \mathrm{TnT}+\mathrm{ve}, 12 / 27 \text { (44\%) hsTnT +ve. Across } 42 \text { patients } \\
\text { with either idopathic DCM or inflammatory CM, LGE extent correlated } \\
\text { with hsTnT and BNP but not TnT. hsTnT could not differentiate between the CMs. } \\
\text { Across both CMs, increased hsTnT and/or BNP was associated } \\
\text { with adverse CV events }\end{array}$ \\
\hline 2014 & $\mathrm{Li}$ & $\begin{array}{c}\text { TnI } \\
\text { CK-MB }\end{array}$ & 310 acute & $64 / 310(21 \%)$ & $\begin{array}{l}\text { 64/310 (21\%) +ve TnI - larger LVDd/LA/RV diameters, but not LVEF or BNP. } \\
\text { Mean F/U 2.2 years - } 24 / 64(38 \%)+\text { ve TnI died vs 37/246 (15\%) normal TnI. } \\
\text { No difference in CK-MB }\end{array}$ \\
\hline 2014 & Bakal & $\begin{array}{l}\text { hsTnT } \\
\text { BNP }\end{array}$ & 27 chronic & & hsTnT higher in ischaemic CM than DCM, BNP was not different \\
\hline 2015 & Baba & $\begin{array}{l}\text { TnI } \\
\text { TnT } \\
\text { hsTnT } \\
\text { BNP }\end{array}$ & 54 chronic & $\begin{array}{l}15 / 54(28 \%) \\
8 / 54(15 \%) \\
17 / 54(31 \%)\end{array}$ & $\begin{array}{l}\text { 17/54 (31\%) +ve hsTnT, 8/54 (15\%) +ve TnT, 15/54 (28\%) +ve TnI. } \\
\text { During mean } 5.1 \text { years F/U, +ve TnT or hsTnT had significantly more CV events } \\
\text { than -ve. +ve TnI did not. Only +ve hsTnT was an independent predictor } \\
\text { of all CV events. CV events varied with hsTnT levels also. LVDd, LVDs and LVEF } \\
\text { were similar at baseline between hsTnT + ve and -ve, but significantly different } \\
\text { (worse in +ve) after F/U }\end{array}$ \\
\hline 2015 & Raimondi & TnI & 66 acute & $35 / 66(53 \%)$ & Children followed for 2.2 years. TnI and inflammation on CMR predicts LV recovery \\
\hline
\end{tabular}

CHF, congestive heart failure; CM, cardiomyopathy; DCM, dilated cardiomyopathy; LVDd LV, diastolic diameter; LVEF, left ventricular ejection fraction. CK, creatine kinase; CK-MB, creatine kinase MB isoform; CV, cardiovascular; ICD, implantable cardioverter defibrillator; LA, left atrial; LVDd, left ventricular diameter in diastole; LVDs, left ventricular diameter in systole; LVEF, left ventricular ejection fraction; F/U, follow up; RV, right ventricular. 
Table 6. Summary of the role of troponin measurement in cardiomyopathy. Staging refers to the association of elevated troponin levels with clinical markers of advanced disease. See text for details.

\begin{tabular}{|c|c|c|c|}
\hline & $\begin{array}{l}\text { Prevalence \% Diagnosis } \\
\text { Median (range) }\end{array}$ & Staging & Prognosis \\
\hline Hypertrophic cardiomyopathy & $36(4-66)$ & $\checkmark$ & $\checkmark$ \\
\hline Dilated cardiomyopathy & $27(5-54)$ & $\checkmark$ & $\checkmark$ \\
\hline Restrictive cardiomyopathy & - & & \\
\hline Left ventricular non-compaction & 17 & & $\checkmark$ \\
\hline Arrhythmogenic right ventricular cardiomyopathy & - & & \\
\hline Anderson Fabry disease & $37(21-40)$ & $\checkmark$ & \\
\hline Takotsubo cardiomyopathy & 87 & & $\checkmark$ \\
\hline Amyloid & - & $\checkmark$ & $\checkmark$ \\
\hline Chagas cardiomyopathy & $\checkmark$ & $\checkmark$ & \\
\hline Peripartum cardiomyopathy & 31 & & \\
\hline
\end{tabular}

reported elevated $\mathrm{TnI}$ in $37 \%$ patients and found a normal TnI level had a high negative predictive value regarding the presence of a LVH. ${ }^{82}$ This was confirmed in an independent cohort of 75 patients followed for over 3 years; elevated hs-TnT was found in $40 \%$ patients and correlated with extent and progression of LGE detected by CMR indicating it is a potential marker of cardiomyopathy progression in AFD ${ }^{83}$ A recent study found similar associations of TnT with LGE and LVH, but also T2 mapping a technique sensitive to myocardial inflammation and oedema. ${ }^{84}$

\section{Takotsubo cardiomyopathy}

Takotsubo cardiomyopathy (TTC) is characterized by transient regional systolic dysfunction involving the left ventricular apex in the absence of obstructive coronary disease on coronary angiography. ${ }^{85}$ There is an increase in $\mathrm{TnI}$ and $\mathrm{TnT}$, typically at lower levels than acute myocardial infarction, but not enough to discriminate between these two disorders at presentation. ${ }^{86}$ During hospitalisation Tn levels increase increased significantly more in acute coronary syndromes (6 fold) compared with TTC (1.8 fold). ${ }^{87} \mathrm{~A}$ large international registry of 1750 patients with TTC found Tn levels were elevated in $87 \%$ patients and an initial Tn measurement of $>10$ times the upper limit of the normal level was an independent predictor of the combined end-point of serious in-hospital complications. ${ }^{87}$

\section{Amyloid cardiomyopathy}

Cardiac amyloidosis is caused by a group of disorders that produce an extracellular deposition of insoluble amyloid fibrils due to aggregation of misfolded proteins. The cardiac phenotype is typically either HCM or RCM and the condition may be inherited (usually due to mutations in transthyretin, TTR) or associated with immunoglobulin light-chain deposition termed AL amyloidosis. ${ }^{88}$ Elevated cardiac Tn levels are associated with a poor prognosis in
AL amyloidosis and are routinely used to stage the disease and stratify treatment. ${ }^{89,90}$ The role of troponins in wild type TTR related amyloid (ATTR) is less well established but a recent study found levels TnI were higher in patients with ATTR amongst a heart failure with persevered ejection fraction (HFpEF) population. ${ }^{91}$

\section{Chagas cardiomyopathy}

Chronic Chagas disease, most prevalent in Latin America, is due to infection with Trypanosoma cruzi. There can be a long silent period before developing overt arrhythmia and heart failure symptoms. Cardiac Tn levels correlate with the severity of the cardiomyopathy and may be useful for monitoring chronic Chagas myocarditis, but are less sensitive than other biomarkers for predicting early disease development in seropositive individuals. ${ }^{92,93}$

\section{Peripartum cardiomyopathy}

Peripartum cardiomyopathy (PPCM) is a form of DCM that presents with signs of cardiac failure during the last month of pregnancy or within five months of delivery. ${ }^{94}$ In a prospective multi-centre study of 106 patients with newly diagnosed PPCM surviving over 6 months 31\% patients had elevated TnT levels which negatively correlated with left ventricular ejection fraction (LVEF) at follow-up. ${ }^{95}$ Preeclamptic pregnant women have been reported to have elevated TnI levels. ${ }^{96}$ Although preeclampsia is associated with a higher incidence of PPCM no causal association has been shown.

\section{Future directions}

In many areas of cardiology risk scores are recommended in guidelines to facilitate the management of patients. For example, in acute coronary syndromes, troponin measurement is included in the GRACE (Global Registry of Acute Coronary Events) score..$^{97}$ Even in indiaddition of TnI to the established ESC SCORE viduals free of cardiovascular disease, the
(Systematic COronary Risk Evaluation) has been shown to improve prediction of cardiovascular death and disease in the general population. ${ }^{98}$ In the cardiomyopathies, elevated Tn levels are almost invariably related to poor prognosis (Table 6). Several characteristics associated with its release in HCM indicate its inclusion in risk prediction models, such as HCM Risk-SCD ${ }^{99}$ should be formally evaluated.

Although elevated Tn is recognised in children with cardiomyopathies there have been no systematic studies examining its role. ${ }^{100}$ There are few studies examining serial troponin measurement, which may be more costeffective and time-efficient than, for example, repeated CMR imaging. And despite cardiac troponin gene mutations being a recognised as a cause of cardiomyopathy, it is not known whether genotype influences Tn detection in the circulation.

\section{Conclusions}

Cardiomyopathies need to be considered in the differential diagnosis of patients with elevated troponin, such as in those presenting with chest pain. Cardiac troponins correlate well with several important markers of disease severity and could be useful as a prognostic tool. There is currently insufficient evidence to support their role in routine management of all cardiomyopathies until we know that measurement may lead to clinical benefit and improved outcomes. High sensitivity assays offer an enormous opportunity to improve the detection and management of non-coronary disease and warrant further investigation in larger longitudinal studies.

\section{References}

1. Szent-Gyorgyi A. On conditions in resting muscle and the nature of excitation. Hung Acta Physiol 1946;1:28-32.

2. Marsh BB. A factor modifying muscle fibre synaeresis. Nature 1951;167:1065-6.

3. Weber A. On the role of calcium in the activity of adenosine 5'-triphosphate hydrolysis by actomyosin. J Biol Chem 1959;234:2764-9.

4. Ebashi S. Third component participating in the superprecipitation of 'natural actomyosin'. Nature 1963;200:1010.

5. Wilkinson JM, Perry SV, Cole HA, Trayer IP. The regulatory proteins of the myofibril. Separation and biological activity of the components of inhibitory-factor preparations. Biochem J 1972;127:215-28.

6. Greaser ML, Gergely J. Reconstitution of troponin activity from three protein com- 
ponents. J Biol Chem 1971;246:4226-33.

7. Wei B, Jin JP. TNNT1, TNNT2, and TNNT3: Isoform genes, regulation, and structure-function relationships. Gene 2016;582:1-13.

8. Anderson PA, Greig A, Mark TM, et al. Molecular basis of human cardiac troponin $\mathrm{T}$ isoforms expressed in the developing, adult, and failing heart. Circ Res 1995;76:681-6.

9. Katrukha IA. Human cardiac troponin complex. Structure and functions. Biochemistry (Mosc) 2013;78:1447-65.

10. Thygesen K, Alpert JS, Jaffe AS, et al. Third universal definition of myocardial infarction. Eur Heart J 2012;33:2551-67.

11. Roffi M, Patrono C, Collet JP, et al. 2015 ESC Guidelines for the management of acute coronary syndromes in patients presenting without persistent ST-segment elevation: Task Force for the Management of Acute Coronary Syndromes in Patients Presenting without Persistent ST-Segment Elevation of the European Society of Cardiology (ESC). Eur Heart J 2016;37:267-315.

12. Chin CW, Shah AS, McAllister DA, et al. High-sensitivity troponin I concentrations are a marker of an advanced hypertrophic response and adverse outcomes in patients with aortic stenosis. Eur Heart J 2014;35:2312-21.

13. Omland T, de Lemos JA, Sabatine MS, et al. A sensitive cardiac troponin $\mathrm{T}$ assay in stable coronary artery disease. $\mathrm{N}$ Engl J Med 2009;361:2538-47.

14. Latini R, Masson S, Anand IS, et al. Prognostic value of very low plasma concentrations of troponin $\mathrm{T}$ in patients with stable chronic heart failure. Circulation 2007;116:1242-9.

15. Katus HA, Looser S, Hallermayer $\mathrm{K}$, et al. Development and in vitro characterization of a new immunoassay of cardiac troponin T. Clin Chem 1992;38:386-93.

16. Cummins B, Auckland ML, Cummins P. Cardiac-specific troponin-I radioimmunoassay in the diagnosis of acute myocardial infarction. Am Heart J 1987;113:1333-44.

17. Hamm CW, Ravkilde J, Gerhardt W, et al. The prognostic value of serum troponin $\mathrm{T}$ in unstable angina. $\mathrm{N}$ Engl $\mathrm{J}$ Med 1992;327:146-50.

18. Antman EM, Tanasijevic MJ, Thompson B, et al. Cardiac-specific troponin I levels to predict the risk of mortality in patients with acute coronary syndromes. N Engl J Med 1996;335:1342-9.

19. Alpert JS, Thygesen K, Antman E, Bassand JP. Myocardial infarction redefined-a consensus document of The Joint European Society of Cardiology/American College of
Cardiology Committee for the redefinition of myocardial infarction. J Am Coll Cardiol 2000;36:959-69.

20. Bertrand ME, Simoons ML, Fox KA, et al. Management of acute coronary syndromes: acute coronary syndromes without persistent ST segment elevation; recommendations of the Task Force of the European Society of Cardiology. Eur Heart J 2000;21:1406-32.

21. Pettersson K, Eriksson S, Wittfooth S, et al. Autoantibodies to cardiac troponin associate with higher initial concentrations and longer release of troponin I in acute coronary syndrome patients. Clin Chem 2009;55:938-45.

22. Kavsak PA. Editorial commentary: highsensitivity cardiac troponin: like every new tool there is a learning curve. Trends Cardiovasc Med 2016 [Epub ahead of print].

23. Giannitsis E, Katus HA. How to avoid inappropriate interpretation and reporting of troponin results measured with high-sensitivity assays in the emergency department. Am J Cardiol 2014;113:904-5.

24. Sherwood MW, Kristin Newby L. Highsensitivity troponin assays: evidence, indications, and reasonable use. J Am Heart Assoc 2014;3:e000403.

25. Cambronero F, Marin F, Roldan V, et al. Biomarkers of pathophysiology in hypertrophic cardiomyopathy: implications for clinical management and prognosis. Eur Heart J 2009;30:139-51.

26. Taniguchi R, Sato Y, Nishio Y, et al. Measurements of baseline and follow-up concentrations of cardiac troponin-T and brain natriuretic peptide in patients with heart failure from various etiologies. Heart Vessels 2006;21:344-9.

27. Nellessen U, Goder S, Schobre R, et al. Serial analysis of troponin I levels in patients with ischemic and nonischemic dilated cardiomyopathy. Clin Cardiol 2006;29:219-24.

28. Sato Y, Yamada T, Taniguchi R, et al. Persistently increased serum concentrations of cardiac troponin $\mathrm{t}$ in patients with idiopathic dilated cardiomyopathy are predictive of adverse outcomes. Circulation 2001;103:369-74.

29. Maron BJ, Gardin JM, Flack JM, et al. Prevalence of hypertrophic cardiomyopathy in a general population of young adults. Echocardiographic analysis of 4111 subjects in the CARDIA Study. Coronary Artery Risk Development in (Young) Adults. Circulation 1995;92:7859.

30. Authors/Task Force m, Elliott PM, Anastasakis A, Borger MA, Borggrefe M, Cecchi F, et al. 2014 ESC Guidelines on diagnosis and management of hyper- trophic cardiomyopathy: the Task Force for the Diagnosis and Management of Hypertrophic Cardiomyopathy of the European Society of Cardiology (ESC). Eur Heart J 2014;35:2733-79.

31. Elliott P, Andersson B, Arbustini E, et al. Classification of the cardiomyopathies: a position statement from the European Society Of Cardiology Working Group on Myocardial and Pericardial Diseases. Eur Heart J 2008;29:270-6.

32. Richard P, Charron P, Carrier L, et al. Hypertrophic cardiomyopathy: distribution of disease genes, spectrum of mutations, and implications for a molecular diagnosis strategy. Circulation 2003;107:2227-32.

33. McKenna WJ, Spirito P, Desnos M, et al. Experience from clinical genetics in hypertrophic cardiomyopathy: proposal for new diagnostic criteria in adult members of affected families. Heart 1997;77:130-2.

34. Kubo T, Baba Y, Hirota T, et al. Differentiation of infiltrative cardiomyopathy from hypertrophic cardiomyopathy using high-sensitivity cardiac troponin T: a case-control study. BMC Cardiovasc Disord 2015;15:53.

35. Hamada M, Shigematsu Y, Ohtani T, Ikeda S. Elevated cardiac enzymes in hypertrophic cardiomyopathy patients with heart failure - a 20-year prospective follow-up study. Circ J 2016;80:218-26.

36. Wallace TW, Abdullah SM, Drazner MH, et al. Prevalence and determinants of troponin T elevation in the general population. Circulation 2006;113:1958-65.

37. Moreno V, Hernandez-Romero D, Vilchez JA, et al. Serum levels of high-sensitivity troponin T: a novel marker for cardiac remodeling in hypertrophic cardiomyopathy. J Card Fail 2010;16:950-6.

38. Pop GA, Cramer E, Timmermans J, et al. Troponin I release at rest and after exercise in patients with hypertrophic cardiomyopathy and the effect of betablockade. Arch Cardiol Mex 2006;76:415-8.

39. Sato Y, Taniguchi R, Nagai K, et al. Measurements of cardiac troponin $\mathrm{T}$ in patients with hypertrophic cardiomyopathy. Heart 2003;89:659-60.

40. Kubo T, Kitaoka H, Okawa M, et al. Serum cardiac troponin I is related to increased left ventricular wall thickness, left ventricular dysfunction, and male gender in hypertrophic cardiomyopathy. Clin Cardiol 2010;33:E1-7.

41. McGorrian CM, Lyster S, Roy A, et al. Use of a highly-sensitive cardiac troponin I assay in a screening population for hypertrophic cardiomyopathy: a case-referent study. BMC Cardiovasc Disord 2013;13:70. 42. Jenab Y, Pourjafari M, Darabi F, et al. 
Prevalence and determinants of elevated high-sensitivity cardiac troponin $\mathrm{T}$ in hypertrophic cardiomyopathy. J Cardiol 2014;63:140-4.

43. Hasler S, Manka R, Greutmann M, et al. Elevated high-sensitivity troponin T levels are associated with adverse cardiac remodelling and myocardial fibrosis in hypertrophic cardiomyopathy. Swiss Med Wkly 2016;146:w14285.

44. Okamoto R, Hirashiki A, Cheng XW, et al. Usefulness of serum cardiac troponins $\mathrm{T}$ and I to predict cardiac molecular changes and cardiac damage in patients with hypertrophic cardiomyopathy. Int Heart J 2013;54:202-6.

45. Cramer G, Bakker J, Gommans F, et al. Relation of highly sensitive cardiac troponin $\mathrm{T}$ in hypertrophic cardiomyopathy to left ventricular mass and cardiovascular risk. Am J Cardiol 2014;113:1240-5.

46. Zhang C, Liu R, Yuan J, et al. Significance and determinants of cardiac troponin i in patients with obstructive hypertrophic cardiomyopathy. Am J Cardiol 2015;116:1744-51.

47. Nakamura S, Takano H, Matsuda J, et al. Prognostic values of highly sensitive cardiac troponin $\mathrm{T}$ and B-type natriuretic peptide for clinical features in hypertrophic obstructive cardiomyopathy: a cross-sectional study. BMJ Open 2014;4:e005968.

48. Kawasaki T, Sakai C, Harimoto K, et al. Usefulness of high-sensitivity cardiac troponin $\mathrm{T}$ and brain natriuretic peptide as biomarkers of myocardial fibrosis in patients with hypertrophic cardiomyopathy. Am J Cardiol 2013;112:867-72.

49. Zhang C, Liu R, Yuan J, et al. Predictive values of $\mathrm{N}$-terminal pro-B-type natriuretic peptide and cardiac troponin I for myocardial fibrosis in hypertrophic obstructive cardiomyopathy. PLoS One 2016;11:e0146572.

50. Gommans DF, Cramer GE, Bakker J, et al. High T2-weighted signal intensity is associated with elevated troponin $\mathrm{T}$ in hypertrophic cardiomyopathy. Heart 2016 [Epub ahead of print].

51. Kubo T, Kitaoka H, Okawa M, et al. Combined measurements of cardiac troponin I and brain natriuretic peptide are useful for predicting adverse outcomes in hypertrophic cardiomyopathy. Circ J 2011;75:919-26.

52. Kubo T, Kitaoka H, Yamanaka S, et al. Significance of high-sensitivity cardiac troponin T in hypertrophic cardiomyopathy. J Am Coll Cardiol 2013;62:1252-9.

53. Kehl DW, Buttan A, Siegel RJ, Rader F. Clinical utility of natriuretic peptides and troponins in hypertrophic cardiomyopathy. Int J Cardiol 2016;218:252-8.
54. Ho CY, Cirino AL, Lakdawala NK, et al. Evolution of hypertrophic cardiomyopathy in sarcomere mutation carriers. Heart 2016 [Epub ahead of print].

55. Japp AG, Gulati A, Cook SA, et al. The diagnosis and evaluation of dilated cardiomyopathy. J Am Coll Cardiol 2016;67:2996-3010.

56. Miettinen KH, Eriksson S, Magga J, et al. Clinical significance of troponin I efflux and troponin autoantibodies in patients with dilated cardiomyopathy. J Card Fail 2008;14:481-8.

57. Watkins H, Ashrafian H, Redwood C. Inherited cardiomyopathies. N Engl J Med 2011;364:1643-56.

58. Soongswang J, Durongpisitkul K, Ratanarapee S, et al. Cardiac troponin T: its role in the diagnosis of clinically suspected acute myocarditis and chronic dilated cardiomyopathy in children. Pediatr Cardiol 2002;23:531-5.

59. Soongswang J, Durongpisitkul K, Nana A, et al. Cardiac troponin T: a marker in the diagnosis of acute myocarditis in children. Pediatr Cardiol 2005;26:45-9.

60. Sramko M, Kubanek M, Tintera J, et al. Utility of combination of cardiac magnetic resonance imaging and high-sensitivity cardiac troponin T assay in diagnosis of inflammatory cardiomyopathy. Am J Cardiol 2013;111:258-64.

61. Aso N, Tamura A, Nasu M. Circulating tenascin-C levels in patients with idiopathic dilated cardiomyopathy. Am J Cardiol 2004;94:1468-70.

62. Bakal RB, Hatipoglu S, Kahveci G, et al. Determinants of high sensitivity troponin $\mathrm{T}$ concentration in chronic stable patients with heart failure: Ischemic heart failure versus non-ischemic dilated cardiomyopathy. Cardiol J 2014;21:67-75.

63. Li X, Luo R, Jiang R, et al. The prognostic use of serum concentrations of cardiac troponin-I, CK-MB and myoglobin in patients with idiopathic dilated cardiomyopathy. Heart Lung 2014;43:219-24.

64. Frankenstein L, Remppis A, Giannitis E, et al. Biological variation of high sensitive Troponin $\mathrm{T}$ in stable heart failure patients with ischemic or dilated cardiomyopathy. Clin Res Cardiol 2011;100:633-40.

65. Baba Y, Kubo T, Yamanaka S, et al. Clinical significance of high-sensitivity cardiac troponin $\mathrm{T}$ in patients with dilated cardiomyopathy. Int Heart J 2015;56:30913.

66. Kuruvilla S, Adenaw N, Katwal AB, et al. Late gadolinium enhancement on cardiac magnetic resonance predicts adverse cardiovascular outcomes in nonischemic cardiomyopathy: a systematic review and meta-analysis. Circ Cardiovasc Imaging
2014;7:250-8.

67. Raimondi F, Iserin F, Raisky 0 , et al. Myocardial inflammation on cardiovascular magnetic resonance predicts left ventricular function recovery in children with recent dilated cardiomyopathy. Eur Heart J Cardiovasc Imaging 2015;16:756-62.

68. Sato Y, Kataoka K, Matsumori A, et al. Measuring serum aminoterminal type III procollagen peptide, $7 \mathrm{~S}$ domain of type IV collagen, and cardiac troponin $\mathrm{T}$ in patients with idiopathic dilated cardiomyopathy and secondary cardiomyopathy. Heart 1997;78:505-8.

69. Miller WL, Hartman KA, Burritt MF, et al. Troponin, B-type natriuretic peptides and outcomes in severe heart failure: differences between ischemic and dilated cardiomyopathies. Clin Cardiol 2007;30:24550 .

70. Kawahara C, Tsutamoto T, Sakai H, et al Prognostic value of serial measurements of highly sensitive cardiac troponin I in stable outpatients with nonischemic chronic heart failure. Am Heart J 2011;162:639-45.

71. Sundstrom J, Ingelsson E, Berglund L, et al. Cardiac troponin-I and risk of heart failure: a community-based cohort study. Eur Heart J 2009;30:773-81.

72. Masson S, Anand I, Favero C, et al. Serial measurement of cardiac troponin $\mathrm{T}$ using a highly sensitive assay in patients with chronic heart failure: data from 2 large randomized clinical trials. Circulation 2012;125:280-8.

73. Kushwaha SS, Fallon JT, Fuster V. Restrictive cardiomyopathy. N Engl J Med 1997;336:267-76.

74. Finsterer J, Stollberger C, Krugluger W. Positive troponin-T in noncompaction is associated with neuromuscular disorders and poor outcome. Clin Res Cardiol 2007;96:109-13.

75. Erer HB, Guvenc TS, Kemik AS, et al. Troponin and anti-troponin autoantibody levels in patients with ventricular noncompaction. PLoS One 2013;8:e57648.

76. Marcus FI, McKenna WJ, Sherrill D, et al. Diagnosis of arrhythmogenic right ventricular cardiomyopathy/dysplasia: proposed modification of the task force criteria. Circulation 2010;121:1533-41.

77. Kostis WJ, Tedford RJ, Miller DL, et al. Troponin-I elevation in a young man with arrhythmogenic right ventricular dysplasia/cardiomyopathy. J Interv Card Electrophysiol 2008;22:49-53.

78. Lazaros G, Anastasakis A, Tsiachris D, et al. Naxos disease presenting with ventricular tachycardia and troponin elevation. Heart Vessels 2009;24:63-5.

79. Patrianakos AP, Protonotarios N, Nyktari $\mathrm{E}$, et al. Arrhythmogenic right ventricular 
cardiomyopathy/dysplasia and troponin release. Myocarditis or the "hot phase" of the disease? Int J Cardiol 2012;157:e26-8.

80. Weidemann F, Breunig F, Beer M, et al. Improvement of cardiac function during enzyme replacement therapy in patients with Fabry disease: a prospective strain rate imaging study. Circulation 2003;108:1299-301.

81. Feustel A, Hahn A, Schneider C, et al. Continuous cardiac troponin I release in Fabry disease. PLoS One 2014;9:e91757.

82. Tanislav C, Guenduez D, Liebetrau C, et al. Cardiac Troponin I: A Valuable Biomarker Indicating the Cardiac Involvement in Fabry Disease. PLoS One 2016;11:e0157640.

83. Seydelmann N, Liu D, Kramer J, et al. High-sensitivity troponin: a clinical blood biomarker for staging cardiomyopathy in Fabry disease. J Am Heart Assoc 2016;5:6.

84. Nordin S, Kozor R, Bulluck H, et al. Cardiac Fabry disease with late gadolinium enhancement is a chronic inflammatory cardiomyopathy. J Am Coll Cardiol 2016;68:1707-8.

85. Gianni M, Dentali F, Grandi AM, et al. Apical ballooning syndrome or takotsubo cardiomyopathy: a systematic review. Eur Heart J 2006;27:1523-9.

86. Sharkey SW, Windenburg DC, Lesser JR, et al. Natural history and expansive clinical profile of stress (tako-tsubo) cardiomyopathy. J Am Coll Cardiol
2010;55:333-41.

87. Templin C, Ghadri JR, Diekmann J, et al. Clinical features and outcomes of Takotsubo (stress) cardiomyopathy. N Engl J Med 2015;373:929-38.

88. Rapezzi C, Lorenzini M, Longhi S, et al. Cardiac amyloidosis: the great pretender. Heart Fail Rev 2015;20:117-24.

89. Dispenzieri A, Kyle RA, Gertz MA, et al. Survival in patients with primary systemic amyloidosis and raised serum cardiac troponins. Lancet 2003;361:1787-9.

90. Dispenzieri A, Gertz MA, Kumar SK, et al. High sensitivity cardiac troponin $\mathrm{T}$ in patients with immunoglobulin light chain amyloidosis. Heart 2014;100:383-8.

91. Gonzalez-Lopez E, Gallego-Delgado M, Guzzo-Merello G, et al. Wild-type transthyretin amyloidosis as a cause of heart failure with preserved ejection fraction. Eur Heart J 2015;36:2585-94.

92. Saravia SG, Haberland A, Bartel S, et al. Cardiac troponin T measured with a highly sensitive assay for diagnosis and monitoring of heart injury in chronic Chagas disease. Arch Pathol Lab Med 2011;135:243-8.

93. Keating SM, Deng X, Fernandes F, et al. Inflammatory and cardiac biomarkers are differentially expressed in clinical stages of Chagas disease. Int $\mathrm{J}$ Cardiol 2015;199:451-9.

94. Elkayam U, Akhter MW, Singh H, et al. Pregnancy-associated cardiomyopathy: clinical characteristics and a comparison between early and late presentation. Circulation 2005;111:2050-5.

95. Hu CL, Li YB, Zou YG, et al. Troponin T measurement can predict persistent left ventricular dysfunction in peripartum cardiomyopathy. Heart 2007;93:488-90.

96. Pergialiotis V, Prodromidou A, Frountzas $\mathrm{M}$, et al. Maternal cardiac troponin levels in pre-eclampsia: a systematic review. J Matern Fetal Neonatal Med 2016;29:338690.

97. Fox KA, Fitzgerald G, Puymirat E, et al. Should patients with acute coronary disease be stratified for management according to their risk? Derivation, external validation and outcomes using the updated GRACE risk score. BMJ Open 2014;4:e004425.

98. Blankenberg S, Salomaa V, Makarova N, et al. Troponin I and cardiovascular risk prediction in the general population: the BiomarCaRE consortium. Eur Heart J 2016;37:2428-37.

99. O'Mahony C, Jichi F, Pavlou M, et al. A novel clinical risk prediction model for sudden cardiac death in hypertrophic cardiomyopathy (HCM risk-SCD). Eur Heart J 2014;35:2010-20.

100. Harris TH, Gossett JG. Diagnosis and diagnostic modalities in pediatric patients with elevated troponin. Pediatr Cardiol 2016 [Epub ahead of print]. 